\title{
Knowledge, Attitude and Practice Towards Guinea Worm among the Resident's of Juba County in Central Equatoria State
}

\author{
Article by Sebit Mustafa Sebit Ebead \\ Ph.D in Public health, Texilla American University, South Sudan \\ E-mail: sebison81@gmail.com
}

\begin{abstract}
Introduction: Dracunculiasis is one of the oldest diseases known to man. Although it is not a killer disease, it is a disease of high morbidity and complications found mostly in farming populations. Its health, social, educational and economic cost to the individual, the household and the community which is considerable and it's transmission cycle are well documented. Key intervention strategies to eradicate guinea worm are safe water supply, vector control using abate, health education and case management.

General objective: To determine the Knowledge, attitude, Practices, towards Guinea Worm Disease in Juba County.

Methodology: The study was a cross-sectional study using both quantitative and qualitative methods of data collection. The quantitative method was face to face interviews while the qualitative method included Key Informants (KIs). It was conducted in Juba county 2015 by the principal investigator (PI) and a group of trained research assistants (RAs) to establish residents' Knowledge, Attitude and Practices, towards Guinea Worm.

Result: More than a quarter of respondents or relative have ever fallen victim of Guinea worm in their life (50/138 (36\%)). A large proportion of respondent perceive drinking infected water was a cause of infection (79/138 (55.7\%)), Most of respondent obtained drinking water from River/Stream (100/232 (43\%)), most respondent said someone with Guinea worm has very much difficulty in farming (63\%), Education level was found to be strongly associated with knowledge on the cause of infection of Guinea worm. $\left(X^{2}=26.249\right.$, d.f. $\left.=6, p>0.000\right)$.

Conclusion: A large proportion of respondent perceive drinking infected water as a cause of infection Guinea worm, More than a quarter of respondent's family member fallen victim of Guinea worm, In general the knowledge attitude and practice of respondent's in Juba County in addition to other confounding factors have had an impact on the Guinea worm eradication

Recommendations: both focused and integrated health education by the health workers need to be emphasized stressing to the communities the importance of Guinea worm eradication. This can be done both at the health unit and through specific and integrated outreaches such as immunization or mass awareness to cover three messages: That Guinea worm comes from contaminated water, Villagers should prohibit a person with blisters or ulcer from entering source of drinking water and that drinking water should be filtered or boiled before drinking.
\end{abstract}

\section{Operation definitions}

Infection: It is the entry of and development or multiplication of infection agent in the body of human or animal.

Case: in epidemiology is person in population or study group identified having a particular disease.

Host: Is a person or other living animal that allow the lodgment to an infection agent under natural condition.

Endemic: Is the situation where there is normally constant number of new cases of the particular disease. 
Texila International Journal of Public Health

Volume 4, Issue 4, Dec 2016

Knowledge: Information, Understanding and skills that you gain through education or experience.

Endemic areas: Areas where a particular disease is constantly present Disease

Prevention: Stopping something bad from taking place

Household: A group of people who normally live together and share activities the can be relatives or friends.

Respondent: A person who answers questions especially in a survey.

Spouse: A husband or wife.

Schedule: A programmed or planned event to be performed

\section{Acronyms}

$\begin{array}{ll}\text { CDC } & \text { Center for Disease Control } \\ \text { CHT } & \text { County } \\ \text { Epi- Info } & \text { Epidemiology Information } \\ \text { GWEP } & \text { Guinea Worm Eradication Program } \\ \text { IDPs } & \text { Internally displaced people } \\ \text { KIs } & \text { Key Informants } \\ \text { MOH } & \text { Ministry of Health } \\ \text { PI } & \text { Principal Investigator } \\ \text { PP } & \text { Pages }\end{array}$

RA Research Assistant

SSGWEP Southern Sudan Guinea worm Eradication Program

WHO World Health Organization

\section{List if appendices}

1. Introduction letter from Kampala International University

2. Proposed work plan and budget

3. Chi-square Table

4. Questioner

5. Key Informants Guide

6. Map of Sudan 
Texila International Journal of Public Health

Volume 4, Issue 4, Dec 2016

\section{Introduction}

\section{Background}

Dracunculiasis is one of the oldest diseases known to man. Although it is not a killer disease, it is a disease of high morbidity and complications found mostly in farming populations. Its health, social, educational and economic cost to the individual, the household and the community which is considerable and it's transmission cycle are well documented. Key intervention strategies to eradicate guinea worm are safe water supply, vector control using abate, health education and case management. (Morenikeji and Adekolu, 2009)

In 1986, WHO designated dracunculiasis as the next disease scheduled to be eradicated by 1995 after smallpox (Hopkins and Ruiz-Tiben, 1991). This eradication deadline was not met and WHO then hoped to certify eradication by 2005. At the 2006 World Health Assembly (WHA) in Geneva, WHO discussed additional measures needed to stop transmission in all of the remaining endemic countries by the end of 2009 (Olajumoke, 2010).

At the beginning of the 20th century, guinea-worm disease was widespread in many countries in Africa and Asia. It is estimated that there were about 50 million cases in the 1950s. Due to concentrated efforts by the international community and the endemic countries, the number of cases of guinea-worm disease was reduced to about 96000 by 1999. Guinea-worm disease is prevalent in only 13 countries in Africa including Sudan, Nigeria, Ghana, Burkina Faso, Niger, Togo and Côte d'Ivoire. A small number of cases have also been reported in Uganda, Benin, Mali, Mauritania, Ethiopia and Chad (WHO, 2001).

There has however been tremendous progress towards the eradication of the disease. The World Health Assembly in 1986 reported that an estimated 3.5 million persons in 20 countries had the disease and approximately 120 million persons were at risk of infection in 1986. By the end of 2002, annual incidence of the disease had been reduced by more than $98 \%$. The burden of guinea worm disease today occurs in Sudan, Ghana and Nigeria. These three countries account for 93\% of all cases worldwide (Morenikeji and Adekolu, 2009).

Dracunculiasis, guinea worm disease, is an incapacitating disease affecting people in poor, remote areas of Africa, Yemen, and a few remaining areas of the Indian subcontinent where there is poor access to protected water sources. The neglect of this preventable disease and its belated recognition are analyzed within the context of changing priorities for health since the 1870s, especially the shift from the paradigm of imperial medicine to primary health Care (John, 1997)

According to Carter center (2009), reported that the disease is endemic in only six African countries: Ethiopia, Ghana, Mali, Niger, Nigeria and Sudan. WHO and its main partner, The Carter Center, are consolidating support from the international community, donors, partners and political leaders in endemic countries and communities in order to eradicate guinea worm disease

The challenge now is to interrupt and contain transmission of all cases by the end of 2009 and subsequently achieve eradication of the disease. It is crucial to implement stricter methods of reporting as the number of cases becomes fewer. WHO is now calling for uninterrupted surveillance in all endemic areas of countries at risk for a resurgence or outbreak of the disease (Carter Center, 2009).

In January-November 2007, Southern Sudan reported 6,068 cases, which is a reduction of $60 \%$ from the 15,054 cases estimated to have occurred during the same period of 2006 The cases in 2007 were reported from 2,114 villages, including 1,881 villages with indigenous cases. During the same period, Southern Sudan exported 2 cases to the northern states of Sudan, 3 cases to Ethiopia, and 4 cases to Uganda. 74\% (4675) of cases in 2007 were in persons 15 years of age and older, while 52\% (3279) of cases were in males. Forty-nine percent of cases were reportedly contained in 2006 and again in 2007, while the rate of reporting from endemic villages improved from 63\% in 2006 to $75 \%$ in 2007 (WHO, 2008). 
Texila International Journal of Public Health

Volume 4, Issue 4, Dec 2016

Sudan is the world's largest reservoir of guinea worm disease, with 70 per cent of the 35,000 cases provisionally reported in 2003. Ghana and Nigeria are the next largest endemic countries (CDC, 2003).

Sudan has now reported a provisional total of 20,581 cases (49\% contained) from 3,264 endemic villages in January-December 2006, with an average reporting rate of $59 \%$ among endemic villages. A total of 19,232 villages in South Sudan are under surveillance. UNICEF/South Sudan has completed 8 of 20, boreholes originally promised in Eastern Equatorial State's highly endemic Kapoeta County during 2006. The 8 villages concerned reported 556 of cases of dracunculiasis in 2006. None of the 13 existing boreholes scheduled for rehabilitation were rehabilitated, which could have impacted another 2,406 cases in those communities (CDC, 2007).

The number of people with guinea worm disease in the Sudan had dropped appreciably from 20,581 to 5,585 cases in 2007 (MOH southern Sudan, 2008).

According to Guinea worm eradication program status of indicators in endemic villages during 2006-2008, villages reporting indigenous cases in 2006 were 3,137 with number of cases 20, 581, while in 2007, villages reporting indigenous cases were 1,765 with number of cases 5,815 and in 2008 villages reporting indigenous cases were 947 out of 2,301 endemic villages, the reported cases is 3,618 (MOH, 2008).

About 73\% of the cases of Guinea worm reported in 2008 were from Sudan, a total of 2185 new cases from 841 villages in southern Sudan (SSGWEP, 2009).

Southern Sudan contains approximately 86 percent of all remaining cases of Guinea worm disease in the world, while Juba county report 125 cases mostly in two Payam/ sub county in 2010 (CDC, 2010).

\section{Statement of the problem}

Protracted war in south Sudan has resulted in a general collapse of formerly existing health program, the urgent of this situation has recently changed dramatically with many people returning to their villages including investors, the evidence of the phenomenal population build up and lack of water and sanitation services make Sudan to remain the greatest challenge to Guinea worm disease eradication; it reported approximately 20,300 cases in 2006, a significant but expected increase from the 5,569 reported in 2005. Southern Sudan contains approximately 86 percent of all remaining cases of Guinea worm disease in the world (CDC, 2010).

The effects of the disease are crippling. Its victims develop large ulcers, usually in the lower leg. The ulcers swell, at times to the size of a tennis ball, and burst, releasing a spaghetti-like parasitic worm ranging in length from $500-800 \mathrm{~cm}$. Victims experience a pain so excruciating that they say it feels as if their leg is on fire. Anecdotal evidence County health office shows that the problem is wide spread in two pay am, It has been long standing, affecting mainly those who are poorly educated, the low socio-economic status, and single mothers or parents.

The Southern Sudan Guinea Worm Eradication Program oversees a community-based system that supports active surveillance, monthly reporting of cases, health education, distribution of cloth and pipe filters,

In trying to solve this problem the county and partnership with NGOs, through the community own resource persons has tried to increase community mobilization for health, targeting especially the opinion leaders. This effort however has not changed the situation a lot.

A study needed to be carried out to fine out factors that have lead to occurrence of the disease, and means of prevention strategies.

\section{Research questions}

1. What are the factors responsible for the high prevalence of Guinea worm among the resident's of Juba County? 
2. What is the knowledge of the respondents, towards Guinea worm among the resident's of Juba County?

3. What are the attitudes of the respondents, towards Guinea worm?

4. What are the practices of respondents, towards Guinea worm?

\section{General objective}

To determine the Knowledge, Attitudes, Practices, towards Guinea Worm Disease in Juba County.

\section{Specific objective}

1. To determine socio-demographic profile of respondents of Juba County.

2. To assess the level of knowledge and practices towards prevention of Guinea worm among the resident's of Juba County.

3. To determine the attitudes of the respondents towards Guinea worm eradication program in Juba County.

\section{Justification}

Humans are the only known reservoirs for guinea-worm disease, so provision of poor water in remote rural areas of Juba Sub County, increase the infection of guinea-worm. About $86 \%$ of the cases of Guinea worm reported in 2009 were from Sudan. (SSGWEP.2010)

Every case of guinea worm disease posed a potential health risk to the community and should therefore be reported to the health authorities, the continuous movement of internally displaced people (IDPs), returnees and soldiers is a factor that could interrupt efforts to eliminate guinea worm in southern Sudan. In conditions of severe limitations of infrastructure services and skilled human resource in post conflict Southern Sudan, developing hygiene and sanitation framework and utilizing affordable community based communication strategies would yield positive results. This would facilitate knowledge base intervention, which includes the following:

- $\quad$ Findings of the KAP Survey will support the development of sound and evidence-based.

- Communication strategies and sector specific interventions for behavior change in endemic village.

- The study will support and serve as an instrument for planning for the line ministries of the GOSS and all sector partners for acceleration of outreach and coverage for effective and efficient interventions in the eradication guinea worm, prevention and other water borne diseases.

- The Survey findings will significantly contribute to the development of long term sustainable program intervention that would influence the guinea worm eradication program at the operational stage.

Therefore, in addition to increasing community mobilization, a study on KAP needed to be carried out to find out in order to determine whether they are among the potential factors contribute to the occurrence of the diseases in the study area.

\section{Literature review}

\section{Background}

There is evidence that Dracunclus medinensis had been identified as early as 1530 BCE. It is also believed to be referenced in the Bible in Numbers as the fiery serpents set upon the Israelites

"And they journeyed from mount Hor by the way of the Red sea, to compass the land of Edom: and the soul of the people was much discouraged because of the way. And the people spake against God, and against Moses, Wherefore have ye brought us up out of Egypt to die in the wilderness? for there is no bread, neither is there any water; and our soul loatheth this light 
Texila International Journal of Public Health

Volume 4, Issue 4, Dec 2016

bread. And the LORD sent fiery serpents among the people, and they bit the people; and much people of Israel died. Therefore the people came to Moses, and said, We have sinned, for we have spoken against the LORD, and against thee; pray unto the LORD, that he take away the serpents from us. And Moses prayed for the people. And the LORD said unto Moses, Make thee a fiery serpent, and set it upon a pole: and it shall come to pass, that every one that is bitten, when he looketh upon it, shall live. And Moses made a serpent of brass, and put it upon a pole, and it came to pass, that if a serpent had bitten any man, when he beheld the serpent of brass, he lived". Numbers 21:4-9. (Kelly and perera, 2006).

According to this passage, however, the fiery serpents kill many of the Isrealites and so do not seem to be the same as $\mathrm{D}$. medinensis which have a low mortality rate. It is also speculated to be a potential origin of the Staff of Life, also called the Rod of Asclepius, which is represented as a serpent wrapped around a staff. Because of the treatment for Guinea Worm Disease involves wrapping the parasite around a stick, it is thought to be related to this common medical image. Additionally it has been thought the image may be reference to pole described in the same passage in Exodus that the fiery serpents appear in. (Cairncross el al, 2002).

\section{Etiology of guinea worm}

The guinea worm, or Dracunclus medinesis, is a nematode transmitted through drinking water. A person drinking stagnant water containing water fleas (copepods/Cyclops) infected with mature, third-stage, guinea worm larvae. When the copepods reach the stomach, they are broken down and the larvae released. The larvae move to the free abdominanal apace. The gravid female is found in the subcutaneous tissue, especially legs, feet and knees, and rarely of other parts of the body. Where they grow for two months and then mate, after mating the male worm dies and adult female worm migrate through tissues, usually to the lower extremities of the human body. Growing and maturing as the year progresses. About a year after the hosts' ingestion of infected water, the worm releases first-stage larvae. The first-stage larvae can survive in the water without a host (copepods) for up to three days. After having been eaten by the water flea, the larvae develop within the fleas body for two weeks to a third-stage larvae, again ready to infect people, there is no animal reservoir for disease (Pedro and Boris, 1987).

\section{Life cycle of guinea worm}

The lifecycle of Dracunclus medinensis involves an intermediate host, a copepod usually of the genus Cyclops, and the definitive host, humans. Larvae in water are digested by the copepods, called water fleas, where they develop into the infective stage after 10-14 days. Water infected with water fleas are drank by humans. Once ingested, stomach acid disintegrates the water flea, exposing the larvae. The larvae will then travel through the small intestine to the body cavity. The large female and the small male will mate in a 10-14 month time period. After mating the male, who has reached approximately 1.2-2.9 cm, dies and is absorbed by the female which, afterward, reaches $60-100 \mathrm{~cm}$. Now the female contains within her thousands to millions of larvae. She will migrate through the body, usually to a lower extremity, reach the surface and die. She will begin to expel from the body. When the exposed parasite comes into contact with water, larvae detach and infect the water. Perhaps because of the parasites migration from the intestinal tract to body tissue, it is thought to be an ancestral link between parasites of the digestive tract and filarial parasites of the tissue (Susan, 1998). 


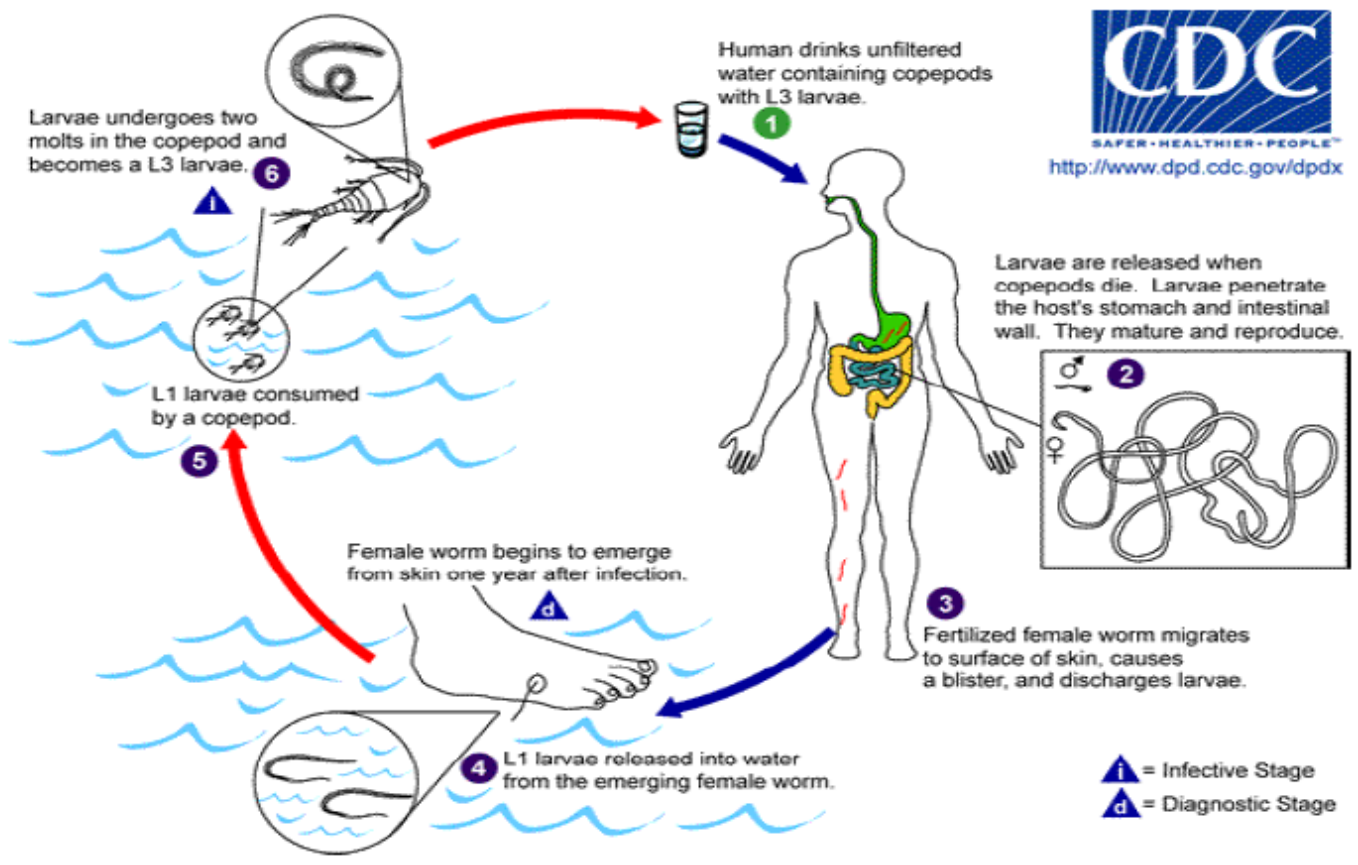

Figure 1. Life cycle of Drucunculusis (Daahir and Abdurahman, 2006)

\section{Source of infection and mode of transmission of guinea worm}

The disease is found in rural areas and is directly related to a lack of clean water in poor areas in arid regions or in parts of the tropics and subtropics with prolonging dry session. In the latter areas, maximum transmission occurs in the dry session when lagoons, ponds, and other bodies of water are at a low level and the density of infected copepods increases. In addition, the scarcity of usually forces the inhabitants to report to any sources available (Pedro and Boris, 1987).

The human host contaminates water with the larvae that escape from the emerging parasite, and in turn becomes infected by ingesting copepods, the intermediate hosts of Dracunculus medinesis, with water; the infection has a markedly seasonal character for tow reason:

1. The influence of climate on the water supply

2. The development cycle of parasite (Ralph, 1979)

In desert climates, however, transmission of the infection is more frequent in the rain session. The disease debilitates them at a time when they must be most agriculturally productive. ( $\mathrm{MOH}$, 2009).

In some areas, transmition may be greater in the dry season when people visit few pools. (Erik, 1999)

The scarcity of water usually forces the inhabitants to resort to any source available, the main sources of infection for man are shallow lagoons, ponds, well dug in dry river beds, wells that people must enter by means of access steps to obtain water. Copepods harboring the third stage larva constitute the infective element; the can only live in still water (Pedro and Boris, 1987).

In KAP study carried out in western Nigeria revealed that, majority of respondent $81.5 \%$ of those from the infected villages knew infection was from drinking infected water, while $61.2 \%$ knew in the villages at risk of infection (Morenikeji and Adekolu, 2009). 
Texila International Journal of Public Health

Volume 4, Issue 4, Dec 2016

\section{Clinical picture}

An inching and painful blister develops at the where the adult female worm emerge, thus making an ulcer. Ulcer can occur anywhere, but they are most common in body areas which are most likely to come into contact with water, feet, legs and genitals. The location of guinea worm infection was in the lower limbs (Morenikeji and Adekolu2009). The thread-likes worm can be seen in the ulcer (Erik, 1999).

\section{Treatment of guinea worm disease}

The infected parts of the body, mostly legs, were immersed in water when there is a lesion so that the worm can protrude and be wound on a stick. The sites of infection were cleaned with an antiseptic and bandaged to prevent worm from retracting and villagers from dipping the affected part in pond water (Olajumoke, 2010).

The work of Awayumi el.al (2010) on the Socio-economic burden of guinea worm disease in Ogun State: A discriminant analysis approach reveal that substantial numbers of respondents (68\%) still combine traditional methods of treating the disease with orthodox methods.( Awayumi and Sowunmi, 2019)

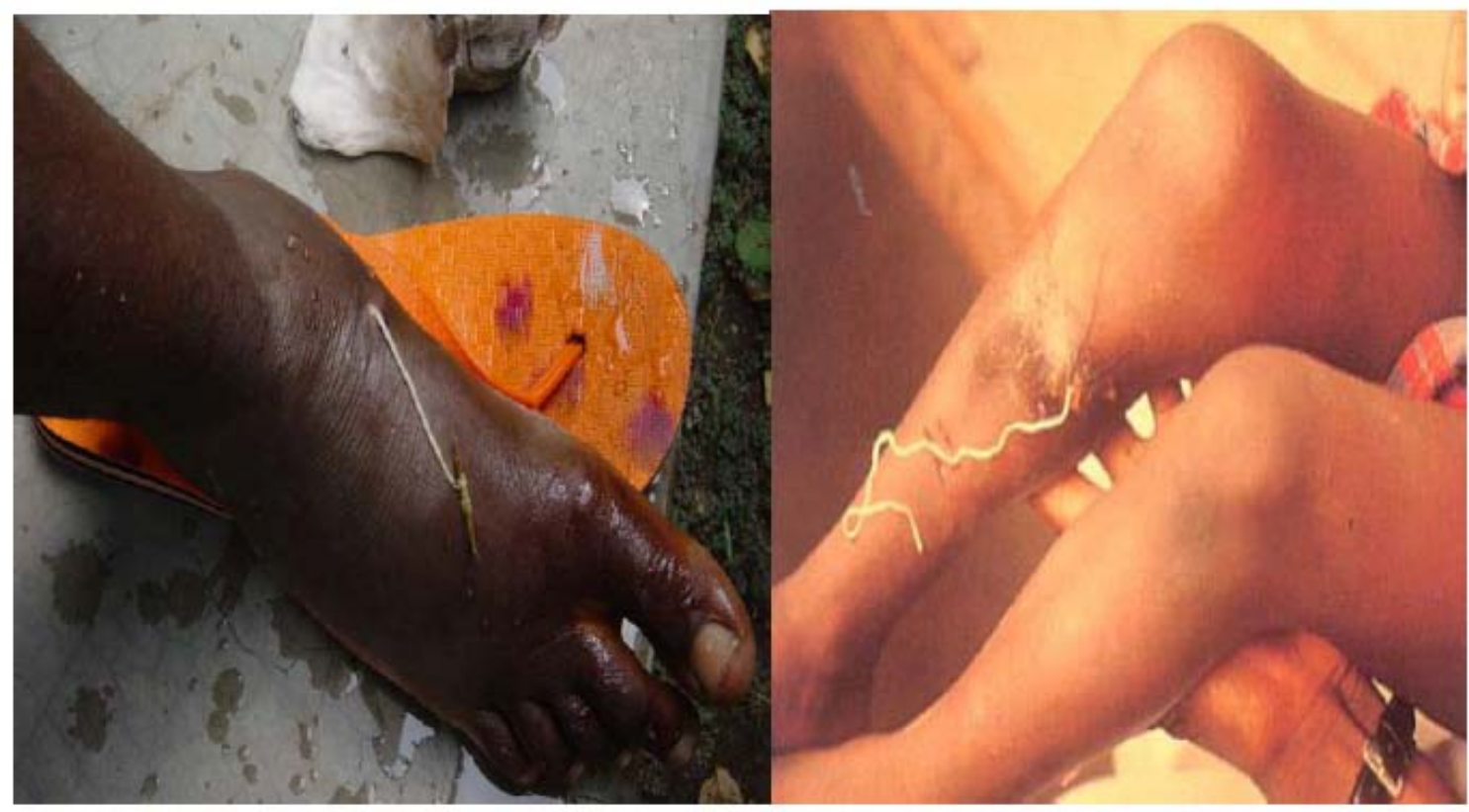

Figure 2. Worm emerge from patient leg, thus making as ulcer

\section{Economic impact of guinea worm}

Health care is consumption good as well as an investment good. As a consumption good, health care improves welfare, while as an investment commodity, health care enhances the quality of human capital by improving productivity and increasing the number of days available for productive activities. In fact, the time lost in production because of ill health indicates reduced output. This in part explains why guinea worm as a parasite that can cause ill health, has attracted a lot of studies ( Awayumi and Sowunmi, 2019)

A study carried out by Olunjde, (2008) high lighted the farmers perception on the effect of guinea worm disease on the level of their agricultural production revealed that $95.8 \%$ of them perceived that guinea worm disease had effect on the level of agricultural production, while $4.3 \%$ of them perceived that guinea worm disease had no effect on the level of their agricultural production. 
In Study in Nigeria, found that because of the disease, women were unable to care normally for themselves, their children, or their households or do other work that would add income to the family. The study of one of these two areas indicated that more than half the children who failed to appear for immunizations did so because their mothers were too ill with the disease to leave home and bring them to the clinic (David, 1990).

Morenikeji and Adekolu (2009) mentioned that 87.2\% of those infected before claimed that the infection had very serious effect on their farming activities, 79.5\% said effect of infection on their economic well being for the period of infection was very high and $71.8 \%$ claimed it had very serious adverse effect on their social activities.

The period of absence from the farm may be long where both parent and children are infected by the disease. Those who are able to recover from the attack often abandon rural areas for towns and cities. revealed that large proportion of economically productive individuals of endemic villages are usually affected resulting in decreased agricultural productivity and economic hardship which often lead to rural-urban drift with its attending problems of overpopulation and increase in crime rate (Awayumi and Sowunmi, 2019).

\section{Prevention and control of guinea worm}

This is an example of a condition that can be eradicated if there is stability and community education and involvement (Erik, 1999).

Health education, which is a strong component of guinea worm disease eradication interventions, is believed to be capable of encouraging people to behave in a way that will help prevent the spread of guinea worm disease. Being able to see the link between contaminated pond water and guinea worm disease and behaving in a way to avoid drinking contaminated water offers a prospect of guinea worm disease eradication, while financial assistance from governments and non-governmental organizations towards provision of safe water sources is being awaited (Olunjde, 2008).

Involvement and participation of all community and stakeholders to eradicate Guinea worm, is the key to success. Guinea worm is eradication is about partnership, the most important of which is the partnership between the eradication program and the community (SSGWEP, 2009).

The combination of both persistent education to change behaviour patterns and implementation of measures to provide safe water has been shown to be effective in the reduction of the disease in previous studies (Olajumoke. 2009).

\section{Community base approach to eradication}

Guinea worm can only be eradicated through an intensive community effort. People at risk have the primary responsibility for taking personal and community actions that have proved effective. PCVs and other outsiders can help and promote the community's efforts, but the community must solve its own problems.

Community education is especially critical since the overall objective of the GWEP is to promote WHO's goal of eradicating Guinea worm disease by 1995. Some organizations feel that the five-year goal is unrealistic and demands too heavy a concentration of money and resources; thus some interventions have been aimed at controlling the disease instead of eliminating it. The intention is to reduce the incidence of Guinea worm to a level where public health authorities no longer consider the disease significant. To keep it within accepted limits, these efforts are focused exclusively on those areas that report a high number of cases (David, 1990).

The problem is, however, that rural peasants often move from one place to another, making the disease impossible to contain. Efforts to do so may have to continue indefinitely. in the long run, controlling the disease may be far more costly than conducting a five-year war of annihilation that involves educating the entire population to the causes and effects of Guinea worm. Even if 
Texila International Journal of Public Health

Volume 4, Issue 4, Dec 2016

the target date of 1995 is overly optimistic, waging the campaign may win the war by the year 2000. (David, 1990)

It has been high lighted by (WHO, 1998), that many cultures are reluctant to use health services because they perceive health care providers to be rude, patronizing and insensitive to the context in which they live. Interactions with the providers can be threatening and humiliating and women often feel pressure to make choices that conflict with their own health and fertility goals.

\section{Protection of water from contamination}

It has been mentioned in study carried out in central equatorial state that almost 60 percent of Juba households are using untreated water from the river or Khors as their main sources (Omar and William, 1994).

One approach to interrupting the Guinea worm cycle is to make sure that individuals suffering from emergence of worms do not come into contact with the water source itself.

Villagers can establish restrictions to make sure that no one with an open wound is allowed to draw water from the common water supply. Someone else can draw water for the person as long as the wounds continue (David, 1990).

As an additional protection, villagers can build platforms over their springs and ponds so that people can lower their buckets and draw water without setting foot in the water. Around shallow wells, they can place simple aprons and walls to prevent water from spilling against people's feet, becoming contaminated, and washing back into the well (David, 1990).

In Benin, with the assistance of UNICEF, the government is helping villagers dig infiltration galleries next to existing ponds. A sand dam allows the water to infiltrate from the pond into the gallery, which is protected to keep it free of the disease-carrying copepod or water flea (David, 1990).

\section{Filtration of contaminated water}

Filtering water to remove the disease-bearing flea is the most common method national programs in Africa are employing to deal with the Guinea worm problem. The method is easy and economical. Monofilaments of fine mesh gauze are being distributed to individuals and families so that they can filter the water in their homes. Ordinary cloth, folded over twice, is also being used for this purpose. Whenever possible, boiling the water is recommended as an added safeguard (David, 1990).

A study carried out by (Morinikeji and Adoklu, 2009) indicated that the water treatment mostly practiced by the respondents that treat water (67(88.2\%)) was filtering. 


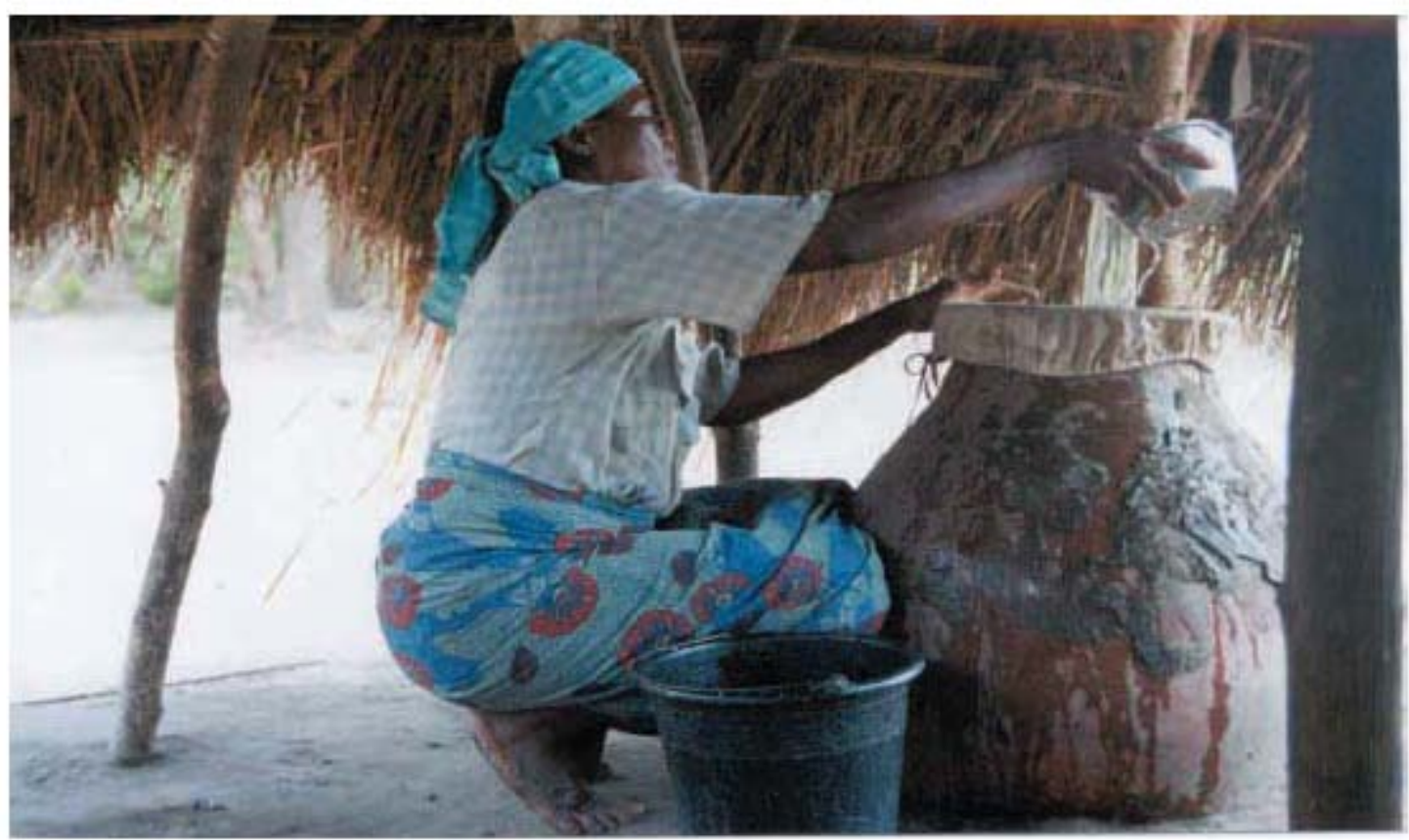

Figure 3. A woman practicing Filtering of cloth in endemic village

\section{Chemical treatment}

Some national programs have sent government health workers to local communities to treat the water supply with the chemical temephos, also known by the brand name, Abate. The World Health Organization has endorsed the use of temephos as a safe mans of vector control. It only takes a small amount (1 mg. per litre) or 1 part per million of temephos to kill copepods; when applied in this amount, it will not harm humans, domestic animals, or fish.

The correct calculation of the volume of the water source and the amount of temephos to be added is of highest priority since any miscalculation may cause serious problems. If too much temephos is added, it can harm or kill other animals which live in or drink the water; if too little is added, it will not kill the copepods(David, 1990).

During the campaign to eradicate dracunculiasis, there has never been a single incident of human toxicity related to the use of ABATE larvicide (Temephos), including during the eradication campaign in Uganda. The ABATE larvicide's formulation for GWEPs is the 50\% emulsifiable concentrate, and the standard dose used for control of copepod populations in stagnant sources of drinking water is one part per million, as recommended by the WHO Expert Committee on Insecticides.12 Assurance of safety of use of ABATE larvicide in actual or potential sources of drinking water is a function of the thorough training of ABATE larvicide application teams, adherence to the CDC Guidelines for Chemical Control of Copepod Populations in Dracunculiasis Eradication Programs, and the experience of ABATE larvicide application cadres in its use.( John et al, 2006)

It is not appropriate to use vector control in every affected village. If a village's source of drinking water is a large pond or lake, it may be too expensive to treat that much water. The suggested maximum size is 500 cubic meters of water. The chemical is added according to the amount of water the source contains. The application is easy: The chemical is mixed in a bucket with some water and sprayed or poured uniformly over the surface of the water. It will start to kill the copepods immediately. Temephos treatment should be scheduled in advance according to the peak Guinea worm season in that village or area. The community must be willing to cooperate, 
Texila International Journal of Public Health

Volume 4, Issue 4, Dec 2016

and health workers must first obtain permission from the village leaders to apply the temephos. (David, 1990)

The social impact of guinea worm disease is mainly attributable to the temporary disability suffered by the patient. Two longitudinal studies in Nigeria $(5,143)$ found that 58 to $76 \%$ of patients were unable to leave their beds for approximately a month during and after emergence of the worm. "The impact of this temporary disability is reinforced by the seasonal pattern of worm emergence; often peaking at stages of the agricultural year when the labor is maximum demanded.

Means of eradication are simple and hoped to be used as a demonstration of success for other eradication projects. Disease control efforts have universally moved from treating and preventing against individual infection to community protection, prevention, and eradication. (Kelly, 2006)

\section{The eradication initiative}

Guinea worm disease is a promising candidate for successful eradication. The cyclops is not a mobile vector like a mosquito, and the carrier state in both the cyclops and human hosts is of limited duration. Diagnosis is easy and unambiguous; cheap and effective measures are available to prevent transmission. The disease has a limited geographical distribution, and even within this area it is found only in certain communities of endemicity. Its markedly seasonal distribution in time also permits a more intensive focus on its prevention in seasonal campaigns. Lastly, as discussed above, transmission from animals to people is practically unknown (Sandy et al, 2002).

One of measures of controlling Guinea worm is that cases are advice not to enter drinking water sources while worm is emerged (Abran, 1995).

\section{Research methodology}

\section{Introduction: study setting}

\section{Study area}

The Study Area was Juba County of central equatorial state, South Sudan, which has been devastated by 22 years of civil warfare. Juba County is one of the two counties found to be endemic for guinea worm disease in central equatorial state, Juba county share boarder with the most infested county in central equatoria state which is Terkeka county. According to 2015 estimated population census, the population of the county was 372413.

The Bomas/villages under survey are Lokiyoro, lopepe, Giimara lunyalaki, and Jur tong paju yawa. These Bomas /villages are known to have a long experience of guinea worm infection they are predominantly farmers and Mundari speaking with Bari dialect. Main water sources in the Bomas /villages include rivers stream and ponds, and a borehole.

\section{Study design}

In this research, the researcher investigated the Knowledge, Attitude and Practices, towards Guinea Worm among residents of Juba Sub County in Sudan.

The study was a cross-sectional study using both quantitative and qualitative methods of data collection. The quantitative method was face to face interviews while the qualitative method included Key Informants (KIs). It was conducted in Juba county 2015 by the principal investigator (PI) and a group of trained research assistants to establish residents' Knowledge, Attitude and Practices, towards Guinea Worm.

\section{Study population}

The study population involves 138 households from Juba County. The study units were the heads of the households or their spouses at Juba County. 


\section{Inclusion and exclusion criteria}

\section{Inclusion}

Any adult in the household found to have roles to play in guinea worm disease control.

Any adult who is able to response appropriate to the questions.

\section{Exclusion}

Al heads of families in Juba Sub County who refuse to participate.

Al heads of families in Juba Sub County who participated in the study then withdraw due to any reason.

\section{Sample size determination}

Kish and Leslie (1965) formula was used to determine the number of the households that ware interviewed.

Sample size:

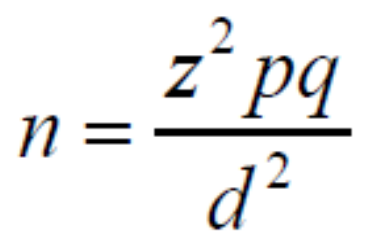

Where $\mathrm{n}=$ sample size

$\mathrm{z}=$ scope corresponding to $5 \%$ level of significance

$\mathrm{d}=$ possible error to be tolerate $(0.05)$

$\mathrm{p}=$ expected population proportion (households) have Knowledge towards Guinea Worm in Juba county $89 \%, \mathrm{P}=(0.9)$. (WHO, 2005)

$\mathrm{q}=(1-\mathrm{p})=0.1$

Therefore, $n=[(1.96) 2(0.9 \times 0.1) /(0.05) 2=3.8416 \times 0.09 / 0.0025=0.345744 / 0.0025=138$

And for the anticipated non-response or badly filled, damaged or lost questionnaire it will be approximated to152respondents by adding $10 \%$.

\section{Sample selection procedure}

Multi stage, cluster sampling, purposive and random sampling methods were done. For key informants, purposive sampling was used while for the community respondents;

For the community a cluster sampling procedure was carried out from county to sub county level to parish (bumas) level;

Out of the fifteen sub counties (Payams) in Juba County, principal investigator selected Northern Bari sub county (Payam) and Tijor sub county (Payam) in Juba County because they are highly infested by Guinea worm and existing of the eradication program activities.

The principal investigator listed down the name of the endemic Parishes (Bumas) which make up Northern Bari sub counties (Payam) and Tijor sub county (Payam) in Juba Sub County.

The name of each endemic parish (Buma) was written in separate paper, and been folded, (to ensure that the entire parish (Buma) have the same chance of being selected.), and then principal investigator randomly pick two papers without replacement.

Lokiyoro and lopepe parishe (bumas) was randomly selected from twenty three parishes (Bumas) which make up Northern Bari sub county (Payam).

The same procedure was done to select Giimara lunyalaki, and Jur tong paju yawa required parishes (Bumas) from ten parishes (Bumas) which make up Tijor sub county (Payam). And this 
Texila International Journal of Public Health

Volume 4, Issue 4, Dec 2016

altogether gave a total of four parishes (Bumas) because each parish (Buma) was having equal chances to be selected, and the four parishes (Bumas) were representative for tow sub counties.

A total of 138 households were interviewed. In order to determine the households that was sampled or interviewed, the principal investigator obtained a list of all the households in parish (Buma) from the parish (Buma) chairpersons.

To ensure the sample of households was more representative; principal investigator calculated the proportion of sample according to each demographical area, to reduce the risk of drawing an extreme sample that is unrepresentative of the population. That was to ensure that equal and enough participants from each parish (Buma) in the sample to make valid comparisons.

To determine how many households to be sample from each parish (Buma). Principal investigator used the following calculations:

Household proportion $=$

Population of the parish (Buma) / Total population $x$ sample size

The same calculation was done to calculate the proportion of households to be interview in the four required parishes (bumas) from two sub counties.

At every required parish (buma), principal investigator identified one area of focus like a market or centred of the where the principal investigator stood and, spin a pen to get the direction of study. Cluster sampling was then done by identifying the first household in that direction for the interview and continued so with every successive fifth household until a total of eligible study units in that village had been interviewed. For the entire selected parish (buma) that make up a total of 138 respondents.

\section{Data collection process}

\section{Primary data}

\section{Quantitative data}

Semi- structured questionnaire was administered by the investigator (PI) and a group of trained research assistants (RAs) to the heads of the households.

Qualitative Data:

Included key informants interviews using KIs question guide. Which was purposively selected to include the following: Juba county health inspector, medical officer from the primary health care centers Northern Bari sub County (Payam) and Tijor sub County (Payam) in Juba County, director of Guinea worm program $\mathrm{MOH}$ central equatorial state, director of Guinea worm eradication program for Army, director of Guinea worm eradication program at carter center.

\section{Secondary data}

Include a summary of existing data. As opposed to data collected directly from respondents or "research subjects" for the express purposes of the study. These secondary data include previous research reports, Books, magazine and journal content, and government and NGO statistics.

\section{Administration procedure}

\section{Training of research assistants}

6 Research assistants fluent in English and Juba Arabic and Bari language, principal investigator selected those ones who had previous experience in data collection and trained them in data collection techniques and how to administer the questionnaire. 


\section{Pre-testing}

Prior to the interviews, the questionnaire was pre-tested in a parishes( bumas) that were not been included in the study so as to identify the difficulties, the mistakes and the misunderstanding in order to correct them.

\section{Field editing of data}

Everyday at the end of the data collection, the principal investigator checked and edit the questionnaire. The experiences and challenges of every day was shared and discussed among the research team and the next day plans was been set.

\section{Missing data}

Where there is a missing data, the research assistants were asked to go back to the field to collect.

\section{Quality control}

Quality was assured through the following:

Competent research assistants was carefully selected and trained.

For the purpose of translation the research assistants was fluent in English and juba Arabic and Bari to make sure that the respondents understand the questions.

The questionnaire was serially numbered to avoid loss and confusion. Field editing of the data was done by the principal investigator and the research assistants for correction of the errors and collection of missing data

Proper identification of key informants who are conversant with Guinea worm disease, Principle investigator select (nonrandom) group of experts who are most knowledgeable of the study issue.

\section{Ethical considerations}

Permission was sought from the from ministry of health central equatorial State through Kampala International University, northern bari payam.

Informed consent was obtained from respondents verbally

Keeping the names of the respondents out of the report ensured confidentiality

The purpose, objectives, benefits of the research outcome and participation procedures was explained to the participants.

\section{Data entry and analysis}

Data was entered EPI INFO 2002 and was analyzed using SPSS software. The information from the heads of the households or their spouses was analyzed and the results were presented as tables and graphs. The KIs interview information was analyzed manually using a master sheet and was presented as texts. Two by two tables was constructed in order to analyze associations between different variables. Chi square test was used to test the observed differences between the dependent and independent variables.

\section{Limitations to the study}

Some heads of households' were not available at their houses during the conduction of the study and this will be minimized by revisiting them and also by conducting the study during the weekends.

Some participants will give responses to impress the research team assuming that they are officials from northern bari payam. It will slightly bias the results. It will be minimized by thorough explanation of the purpose of the study. 
Texila International Journal of Public Health

Volume 4, Issue 4, Dec 2016

\section{Presentation of result, analysis and interpretation}

\section{Social demographic characteristics of respondents}

\section{Gender of the respondents}

The findings showed that majority of respondent's were males (61 \%) and few of them were females (40\%).

Table1. Gender of the Respondents

\begin{tabular}{|l|l|l|}
\hline VARIABLE GENDER & FREQUENCY $(\mathrm{N}=138)$ & PERCENTAGE (\%) \\
\hline Male & 83 & 61 \\
\hline Female & 55 & 40 \\
\hline Total & 138 & 100 \\
\hline
\end{tabular}

Age group of the Respondent $\mathrm{s}$

On age most respondent's age range 30-34 (31 \%), followed by (20 \%) of the respondents who were aged 35-39, (13\%) were aged 40-44 while (10\%) were above 45 years old and aged 20-24, (11\%) were aged 25-29 and few respondent's (4\%) for 15-19.

Table 2. Age group of the Respondents

\begin{tabular}{|l|l|l|}
\hline VARIABLE AGE GROUP & FREQUENCY $(\mathrm{N}=138)$ & $\begin{array}{l}\text { PERCENTAGE } \\
(\%)\end{array}$ \\
\hline $15-19$ & 6 & 4 \\
\hline $20-24$ & 14 & 10 \\
\hline $25-29$ & 15 & 11 \\
\hline $30-34$ & 43 & 31 \\
\hline $35-39$ & 28 & 20 \\
\hline $40-44$ & 18 & 13 \\
\hline $45+$ & 14 & 10 \\
\hline Total & 138 & 100 \\
\hline
\end{tabular}

Ethnicity of the respondents

Most respondent's were Mundari by tribe (65/138 (47\%)) followed by Bari (30 \%) and only Nyangwara (23\%).

Table 3. Ethnicity of the respondents

\begin{tabular}{|l|l|l|}
\hline VARIABLE & FREQUENCY $(\mathrm{N}=138)$ & PERCENTAGE $(\%)$ \\
\hline Bari & 41 & 30 \\
\hline Mundari & 65 & 47 \\
\hline Nyangwara & 32 & 23 \\
\hline Total & 138 & 100 \\
\hline
\end{tabular}

\section{Marital status of the respondents}

On marital status of the respondent's, majority are married (80\%), followed by single (15\%), while only (2\%) were widowed. However most respondent's (48 \%) were Monogamous, followed by (36\%) Polygamous and few (17\%) were single parents. 


\section{Education level of the respondents}

Slightly more than a Half of the respondent's attended primary schools (51\%), while more than a quarter of the respondent's never attended schools (39\%), and few (3\%) were Tertiary.

Table 4. Education level of the respondents

\begin{tabular}{|l|l|l|}
\hline VARIABLE & FREQUENCY $(\mathrm{N}=138)$ & PERCENTAGE $(\%)$ \\
\hline None & 44 & 39 \\
\hline Primary & 70 & 51 \\
\hline Secondary & 20 & 15 \\
\hline Tertiary & 4 & 3 \\
\hline Total & 138 & 100 \\
\hline
\end{tabular}

\section{Occupation of the respondents}

On occupation of the respondent's, it clearly depicts that a large proportion of respondent's were business persons (62/138 (45\%)), followed by (26/138(19\%)) who were peasants, Civil servant accounted for (34/138 (24.6 \%)), few respondent’s unemployed (16/138 (11.6 \%)).

Table 5. Occupation of the respondents

\begin{tabular}{|l|l|l|}
\hline VARIABLE & FREQUENCY $(\mathrm{N}=138)$ & PERCENTAGE $(\%)$ \\
\hline Peasants & 26 & 19 \\
\hline Business man/woman & 62 & 45 \\
\hline Civil servant & 34 & 25 \\
\hline Unemployed & 16 & 12 \\
\hline Total & 138 & 100 \\
\hline
\end{tabular}

\section{Knowledge of guinea worm transmit ion, cause and impact}

Knowledge of Guinea worm and member of family been fallen victim of Guinea worm.

The majority of respondents heard about Guinea worm (136/138 (99\%), while most respondents or relative have not fallen victim of Guinea worm in their life (88/138 (64\%).

Table 6. Knowledge of Guinea worm and member of family been fallen victim of Guinea worm

\begin{tabular}{|l|l|l|l|l|}
\hline VARIABLE & \multicolumn{2}{|l|}{$\begin{array}{l}\text { KNOWLEDGE OF GUINEA } \\
\text { WORM }\end{array}$} & $\begin{array}{l}\text { MEMBER OF FAMILY BEEN FALLEN } \\
\text { VICTIM }\end{array}$ \\
\hline & FREQUENCY $(\mathrm{N}=138)$ & $\%$ & FREQUENCY $(\mathrm{N}=138)$ & $\%$ \\
\hline Yes & 136 & 99 & 50 & 36 \\
\hline No & 2 & 1 & 88 & 100 \\
\hline Total & 138 & $\begin{array}{l}10 \\
0\end{array}$ & 138 & \\
\hline
\end{tabular}

All key informant mention that, the local name for Guinea worm was known as Firindid and Mejeke

Source of information's about Guinea worm cause, effect and prevention methods

A large proportion of respondents got information about Guinea worm from health workers (116/270 (43\%)), while more than a quarter got $t$ from relatives (116/270 (35\%)), only (3/270(1.1)) obtained information’s from Radio. 
Texila International Journal of Public Health

Volume 4, Issue 4, Dec 2016

Table7. Source of information's about Guinea worm cause, effect and prevention methods.

\begin{tabular}{|l|l|l|}
\hline VARIABLE & FREQUENCY $(\mathrm{N}=270)$ & PERCENTAGE $(\%)$ \\
\hline Relatives & 95 & 35 \\
\hline Radio & 3 & 1 \\
\hline Workshops/seminar & 25 & 9 \\
\hline Political/civil leader & 31 & 12 \\
\hline Health worker & 116 & 43 \\
\hline Total & 270 & 100 \\
\hline
\end{tabular}

Multiple responses (270)

\section{Knowledge of Guinea worm Symptoms}

Most respondents said that Pain and Swelling on lower limb was a symptom of Guinea worm (139/291 (48\%)), followed by only (32\%) who said Fever/ stream, and few said Blister on lower $\operatorname{limb}(13.7 \%)$.

Table8. Knowledge of Guinea worm Symptoms

\begin{tabular}{|l|l|l|}
\hline VARIABLE & FREQUENCY(N=291) & PERCENTAGE (\%) \\
\hline Fever/ stream & 92 & 32 \\
\hline Wound on lower limb & 20 & 7 \\
\hline Blister on lower limb & 40 & 14 \\
\hline Pain and swelling on lower limb & 139 & 48 \\
\hline Total & 291 & 100 \\
\hline
\end{tabular}

Multiple responses

\section{Knowledge on the cause of infection of Guinea worm}

A large proportion of respondent perceive drinking infected water was a cause of infection (79/138 (55.7\%)), while a quarter said eating infected food (35/138(25\%) and few mention something else (e.g. Dirtiness) (24/138 (17\%).
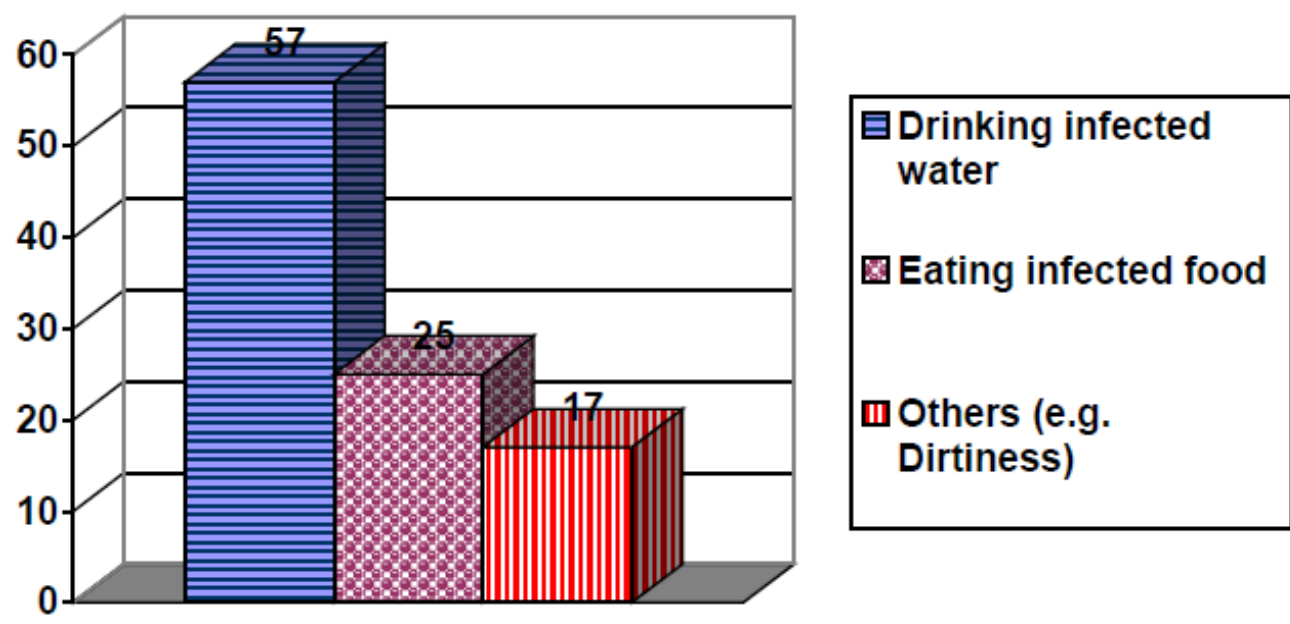

Figure 4. Knowledge on the cause of infection of Guinea worm 
Education level was found to be strongly associated with knowledge on the cause of infection of Guinea worm. (X2=26.249, d.f. $=6$, $\mathrm{p}>0.000)$

\section{Sources of drinking water}

Most of respondent obtained drinking water from River/Stream (100/232 (43\%)), followed by more than a quarter from ponds 80/232(36\%), while only 48/232(21\%) obtain their drinking water from bore-hole.

Table9. Sources of drinking water

\begin{tabular}{|l|l|l|}
\hline VARIABLE & FREQUENCY(N=232) & PERCENTAGE (\%) \\
\hline River / Stream & 100 & 43 \\
\hline Bore-hole & 48 & 21 \\
\hline Well (un protected) & 4 & 2 \\
\hline Others (Ponds) & 80 & 36 \\
\hline Total & 232 & 100 \\
\hline
\end{tabular}

Multiple responses

\section{How community can help in preventing Guinea worm}

Many respondent said community can help in preventing Guinea worm by Educating children and other community members on how to prevent it (119/267 (45\%)). While a quarter reported that community can help in preventing Guinea worm by Communal labour to build boreholes (70/267(26.2\%)), few said they can help by Protecting sources of drinking water.

Table10. How community can help in preventing Guinea worm

\begin{tabular}{|l|l|l|}
\hline VARIABLE & $\begin{array}{l}\text { FREQUENCY(N=267 } \\
\text { Communal labour to build boreholes }\end{array}$ & PERCENTAGE (\%) \\
\hline Commen & 30 & 26 \\
\hline Communal labour to clear bushes / vegetation & 36 & 14 \\
\hline $\begin{array}{l}\text { Educate children and other community } \\
\text { member's on how to prevent G.W. }\end{array}$ & 119 & 45 \\
\hline Protection of water sources & 42 & 16 \\
\hline Total & 267 & 100 \\
\hline
\end{tabular}

Multiple responses

\section{Difficulties associated with Guinea worm disease}

More than half of respondents said someone with Guinea worm has very much Difficult in walking (54\%), while few said they have a little difficulty in walking (26\%). Three quarter of respondents said someone with Guinea worm has very much difficult in running (71\%), while few said they have a little difficulty in running (16\%). Going to farm, most respondent said someone with Guinea worm has very much difficulty in farming (63\%), while only $22 \%$ said they have a little. Majority of respondent said someone with Guinea worm has very much Difficulty in earning enough to the family (76\%) and few said they don't have difficulty in earning enough to their families. 
Texila International Journal of Public Health

Volume 4, Issue 4, Dec 2016

Table11. Difficulties associated with Guinea worm disease

\begin{tabular}{|l|l|l|}
\hline VARIABLE & FREQUENCY(N=138) & PERCENTAGE (\%) \\
\hline Difficult in walking for them & 28 & 20 \\
\hline Not At All & 36 & 26 \\
\hline A Little & 74 & 54 \\
\hline Very much & 138 & 100 \\
\hline Total & 17 & 12 \\
\hline Difficult in running for them & 23 & 17 \\
\hline Not At All & 98 & 71 \\
\hline A Little & 138 & 100 \\
\hline Very much & 20 & 14 \\
\hline Total & 31 & 22 \\
\hline Difficult is it for them to go the farm & 63 \\
\hline Not At All & 87 & 100 \\
\hline A Little & 138 & 14 \\
\hline Very much & 19 & 10 \\
\hline Total & 14 & 76 \\
\hline Difficult in earning enough for the family & 100 \\
\hline Not At All & 105 & \\
\hline A Little & 138 & \\
\hline Very much &
\end{tabular}

\section{Attitude of respondents towards guinea worm}

Respondents Attitudes towards usefulness of Guinea worm eradication program

Majority of respondents perceived Guinea worm eradication program was useful (131/138 (96\%)), while only ( 6/138(4\%)) said was not Useful or useless.
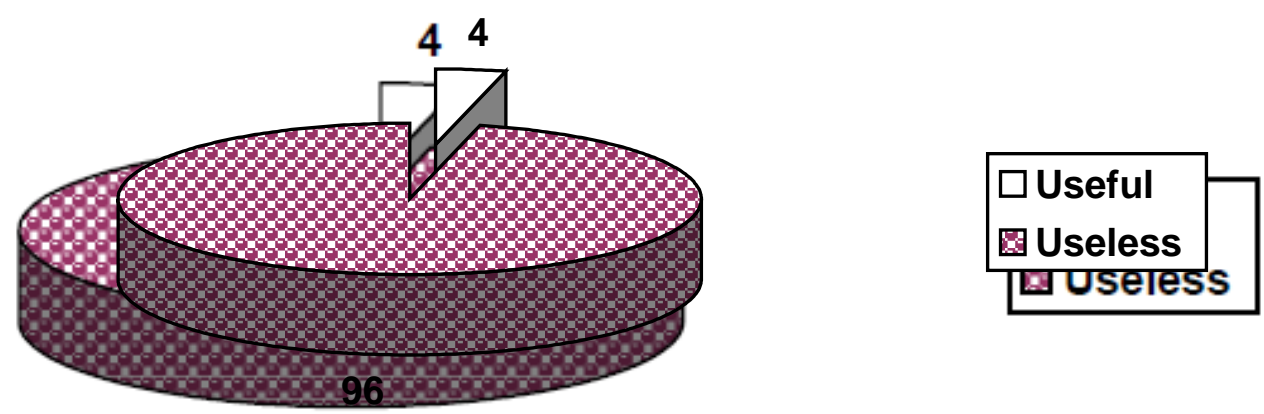

96

Figure5. Respondents Attitudes towards usefulness of Guinea worm eradication program

Chi-square (X2) analysis of age, sex, Ethnicity and Education level and usefulness of Guinea worm eradication program is statistically not significant. 


\begin{tabular}{|l|l|l|l|l|}
\hline Variable & Chi-square & D.F & P-value & Remarks \\
\hline Sex & 0.061 & 1 & 0.805 & NS \\
\hline Age & 38.833 & 2 & 0.301 & NS \\
\hline Ethnicity & 0.314 & 2 & 0.855 & NS \\
\hline Education & 2.919 & 3 & 0.404 & NS \\
\hline
\end{tabular}

\section{Attitude of respondents towards health workers}

A large proportion of respondents perceived health workers as being rude (83/138 (60.6\%)), while only 43/138(31\%) perceived health workers as being friendly.

Table12. Attitude of respondents towards health workers

\begin{tabular}{|l|l|l|}
\hline Variable & Frequency(N=138) & Percentage (\%) \\
\hline Very friendly & 8 & 6 \\
\hline Friendly & 43 & 31 \\
\hline Rude & 83 & 61 \\
\hline Very rude & 3 & 2 \\
\hline Total & 138 & 100 \\
\hline
\end{tabular}

\section{Type of help needed externally to combat Guinea worm}

Most respondents said the external assistant needed to combat Guinea worm, was Technical support to educate people on prevention of Guinea worm (121/280 (43\%)), followed by more than a quarter who said provision of medication and filtrations tools $(94 / 280(34 \%))$, while only 26/280(9\%) said financial support.

Table13. Type of help needed externally to combat Guinea worm

\begin{tabular}{|l|l|l|}
\hline VARIABLE & $\begin{array}{l}\text { FREQUENC } \\
\text { Y(N=280) }\end{array}$ & PERCENTAGE (\%) \\
\hline Financial & 26 & 9 \\
\hline $\begin{array}{l}\text { Technical support to help build bore } \\
\text { holes }\end{array}$ & 10 & 4 \\
\hline $\begin{array}{l}\text { Technical support to help manage } \\
\text { cases in the community }\end{array}$ & 30 & 11 \\
\hline $\begin{array}{l}\text { Technical support to educate people } \\
\text { on prevention of Guinea worm }\end{array}$ & 121 & 43 \\
\hline $\begin{array}{l}\text { Provide medication and Filtrations } \\
\text { tools }\end{array}$ & 94 & 34 \\
\hline Total & 280 & 100 \\
\hline
\end{tabular}

Multiple responses

\section{Ever attended a seminar on guinea worm}

Few respondent reported to ever attended Seminar (25/138(19\%)), while majority 113/138 (82\%) were willing to attend seminar. 
Texila International Journal of Public Health

Volume 4, Issue 4, Dec 2016

Table14. Ever Attended a Seminar on Guinea worm

\begin{tabular}{|l|l|l|}
\hline Variable & Frequency(N=138) & Percentage (\%) \\
\hline Ever attended & 25 & 19 \\
\hline $\begin{array}{l}\text { Willingness to } \\
\text { attend }\end{array}$ & 113 & 82 \\
\hline Total & 138 & 100 \\
\hline
\end{tabular}

How community can be encouraged to participate in eradication program of Guinea worm

Many respondent said conducting meeting with community will encourage community to participate in eradication program (51/138 (37\%)), followed by mass awareness campaign (6/138 (33\%) while only 3/138 (2\%) don’t have any idea.

Table15: How community can be encouraged to participate in eradication program of Guinea worm?

\begin{tabular}{|l|l|l|}
\hline VARIABLE & FREQUENCY(N=138) & PERCENTAGE (\%) \\
\hline $\begin{array}{l}\text { Conduct meeting with community } \\
\text { members }\end{array}$ & 51 & 37 \\
\hline Community mobilization & 38 & 28 \\
\hline Mass awareness campaign & 46 & 33 \\
\hline Don't know & 3 & 2 \\
\hline Total & 138 & 100 \\
\hline
\end{tabular}

\section{Prevention and control of guinea worm}

\section{Community prevention methods}

More than a half of respondents said prohibiting patient from entering water sources was the means of prevention (80/138 (58\%), followed by people who said Filtering of water (32/138(23\%), while only 26/138(19\%) do nothing.

Table16. Community prevention methods

\begin{tabular}{|l|l|l|}
\hline VARIABLE & FREQUENCY(N=138) & PERCENTAGE (\%) \\
\hline Filtering of water & 32 & 23 \\
\hline $\begin{array}{l}\text { Prohibiting patient from } \\
\text { entering water sources }\end{array}$ & 80 & 58 \\
\hline Do Nothing & 26 & 19 \\
\hline Total & 138 & 100 \\
\hline
\end{tabular}

\section{Management of guinea worm patient}

Many respondents said they take patient to traditionalist/herbalist (137/ 237 (58\%)), while 77/237(33\%) reported taking the patient to the hospital and only $23 / 237(10 \%)$ do nothing. 
Table17. Management of Guinea worm patient

\begin{tabular}{|l|l|l|}
\hline VARIABLE & FREQUENCY(N=237) & PERCENTAGE (\%) \\
\hline $\begin{array}{l}\text { Take the person to the } \\
\text { hospital }\end{array}$ & 77 & 33 \\
\hline $\begin{array}{l}\text { Take to the } \\
\text { traditionalist/herbalist }\end{array}$ & 137 & 58 \\
\hline Do nothing & 23 & 10 \\
\hline Total & 237 & 100 \\
\hline
\end{tabular}

Multiple responses

\section{Traditional treatment of guinea worm}

Many respondents traditionally treat G.W by putting the leg on cool water in the morning and wrapping the worm on wire (84/138 (61\%), while only (54/138(39\%) Bandaging the wound and winding the worm on stick.

Table18. Traditional treatment of Guinea worm

\begin{tabular}{|l|l|l|}
\hline VARIABLE & FREQUENCY(N=138) & PERCENTAGE (\%) \\
\hline $\begin{array}{l}\text { Bandaging and winding the worm } \\
\text { on stick }\end{array}$ & 54 & 39 \\
\hline $\begin{array}{l}\text { Putting the leg on cool water in the } \\
\text { morning and warp the worm on } \\
\text { wire }\end{array}$ & 84 & 61 \\
\hline Total & 138 & 100 \\
\hline
\end{tabular}

\section{Water treatment practices at the household level}

Most respondents 62/138(45\%) said they filtered their water before drinking, 29/138(21\%) add chemical, a third of respondents 25/138(18\%) drink their water without treatment, while few 19/138(14\%) practiced sedimentation.
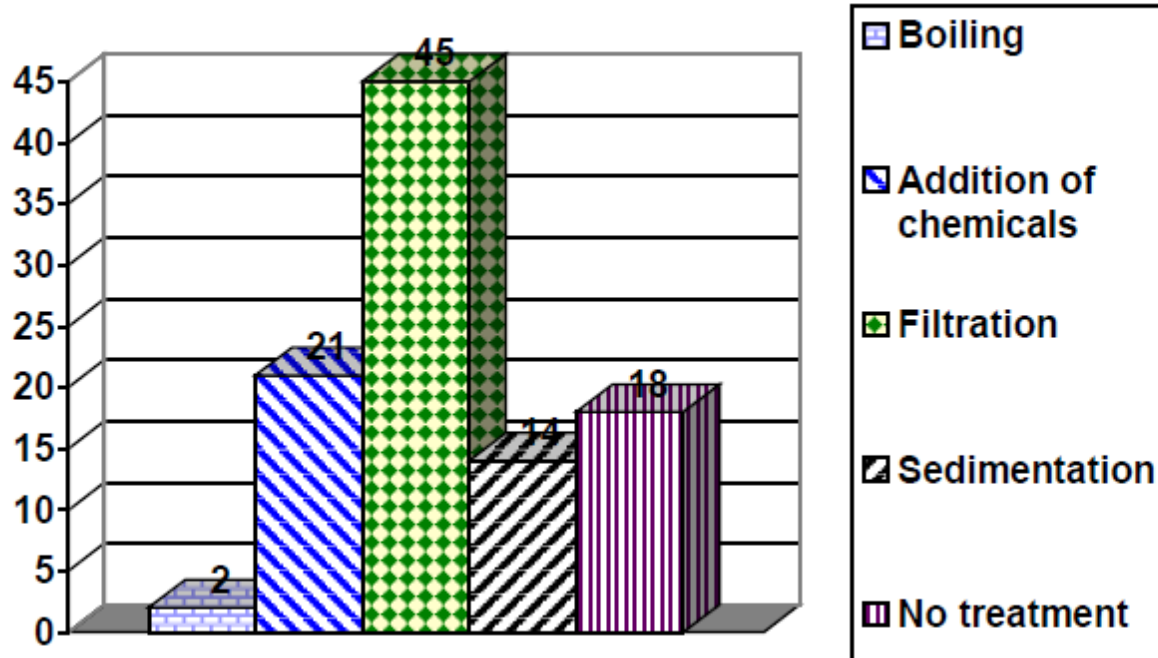

Figure 6. Water treatment practices at the household level 
Texila International Journal of Public Health

Volume 4, Issue 4, Dec 2016

All the key informants reported that some of the villagers still drink the infested water without filtering especially during their grazing or on their way to or from the farm.

2/6 KIs mentioned some villagers especially old people prefer the "natural" taste of pond water or Stream (Khur) and that borehole is salty.

Purpose of filtering cloth

Most respondent's perceive that one of the purpose of filtering cloth is to remove Cyclops m65/138(47.1\%), while only few 27/138(19.6\%) have no idea about the purpose of filtering cloth.

Table19. Purpose of filtering cloth

\begin{tabular}{|l|l|l|}
\hline VARIABLE & FREQUENCY (N=138) & PERCENTAGE (\%) \\
\hline Removing Cyclops & 65 & 47 \\
\hline Cleaning/purifying water & 46 & 33 \\
\hline Don't know & 27 & 20 \\
\hline Total & 138 & 100 \\
\hline
\end{tabular}

All the key informants reported that poor response to report cases of the disease and lack of commitment on the part of field and village volunteer workers are among the factor deteriorating the situation.

\section{Discussion, conclusion and recommendations}

\section{Discussion}

Knowledge of Guinea worm transmission, cause and impact

The study reveals that majority of the respondents have heard about Guinea worm because of the existence of a local name as revealed by the Key informants, Few respondents or relative (36\%) have fallen victim of Guinea worm, the findings is similar to what Olajumoke, (2009) reported (only $38.8 \%$ were infected before in the villages at risk of infection. 51.3\% had been infected before in all the villages).

On education level, half (51\%) of the respondents attended school at least up to primary. These could have got the information about Guinea worm from the health workers during the school health programmes such as immunisation. Other respondents could have got the knowledge from the Guinea worm eradication program efforts of community mobilisation for health through the community health workers.

Some respondents could have, got the information from political and civic leaders, the media like radios and television as well as from others in the community through sharing experiences.

The occupational status of most families was reasonably fair (69\%) given the fact that the respondent's in these families were either businesspersons or civil servants, and yet social economic status is a very important factor of knowledge.

The fact that large proportions of the respondents (43\%) acquired knowledge on Guinea worm from Health workers or by sharing experiences as their most reliable medium of communication in this county, it should not be misunderstood by the general public that Health workers cold be the best means and only medium used for the dissemination of Guinea worm information however, the public should rather know that other means of media such as Radio, Posters, Workshops, Seminars can as well play a big role in disseminating information as far as mass communication is concerned.

In addition, findings revealed that, most respondents (48\%) perceived pain and swelling on the lower limb as a symptom of G.W, this finding agree with what Erik, (1999) affirm that (An 
inching and painful blister develops at the place where the adult female worm emerge, thus making an ulcer).

When respondent were asked what they perceived as the cause of infection, A large proportion (56\%) knew that infection was from drinking infected water, the finding can be compared with Morenikeji and Adekolu (2009) which revealed that majority of respondent (81.5\%) from the infected villages knew infection was from drinking infected water, On the other hand, more than a quarter of respondent (25\%) did not recognise the link between drinking contaminated water and Guinea worm, They still perceived that the infection was from eating infected food (wild animal) meat and only (17\%) reported that infection was associated with Dirtiness. This could have been explained by the fact that social and cultural factors which still influence management of Guinea worm in the county.

Education level was found to be strongly associated with knowledge on the cause of infection of Guinea worm ( $\mathrm{p}>0.000)$.

Furthermore, the finding indicated that most of respondents obtain drinking water from River/Stream (43\%), while almost two quarter (36\%) of respondent's still relied on ponds for their drinking water which are potential breeding ground for guinea worm, this finding can is comparable with Awayumi and Sowunmi, (2009) which indicated that $49 \%$ of respondents still rely on ponds for drinking water, yet in many studies, ponds have been claimed to be the ideal source of dracunculiasis transmission, also Morenikeji and Adekolu (2009) most of the respondents think that the infection is caused by contaminated pond water because cases of infection reduced when pond treatment and filtering of drinking water started. The fact that respond ant's still relied on ponds and stream could be explained by the scarcity of underground water in the area of study which led to exiguity of the bore-hole as affirmed by Key Informant's guide. That is why few (20.7\%) obtain their drinking water from bore-hole. This affirm what (Pedro el al, 1987) mentioned that the scarcity of water usually forces the inhabitants to resort to any source available, the main source of infection for man are shallow lagoons, ponds, well dug in dry river beds, wells that people must enter by means of access steps to obtain water.

Also, many respondent (44.6) said community can help in preventing Guinea worm by Educating children and other community members on how to prevent Guinea worm and this agree with what (Olunjde, 2008) mentioned (Health education, which is a strong component of guinea worm disease eradication interventions, and is believed to be capable of encouraging people to behave in a way that will help prevent the spread of guinea worm disease (Nwosu, 1989). Being able to see the link between contaminated pond water and guinea worm disease and behaving in a way to avoid drinking contaminated water offers a prospect of guinea worm disease eradication. While a quarter (26.2\%) Communal labour was able to build boreholes, few (15.7\%) said by Protection of drinking water sources.

In difficulties associated with Guinea worm disease most respondent (63\%) said someone with Guinea worm has very much difficulty in farming, the finding is similar to a study carried out by Olunjde, (2008) which highlighted that, (the farmers perception on the effect of guinea worm disease as for the level of their agricultural production revealed that $95.8 \%$ of them perceived that guinea worm disease had effect on the level of agricultural production). The finding also can be compared with Morenikeji and Adekolu (2009) who mentioned that (87.2\%) of those infected before claimed that the infection had very serious effect on their farming activities, while (79.5\%) said that the effect of infection on their economic well being for the period of infection was very high and (71.8\%) claimed it had very serious adverse effect on their social activities.

The study shows that majority of respondent (76\%) said someone with Guinea worm has very much difficulty in earning enough income for the family. this agree with a study in Nigeria, which found out that, women were unable to care normally for themselves, their children, or their households or do other additional work that would increase income to the family. The study 
Texila International Journal of Public Health

Volume 4, Issue 4, Dec 2016

indicated that more than half of the children who failed to appear for immunizations did so because their mothers were too ill with the disease to leave home and bring them to the clinic (David, 1990).

The period of absence from the farm may be long where both parent and children are infected with the disease. Those who are able to recover from the attack often abandon rural areas for towns and cities. Greenaway (2004) revealed that large proportion of economically productive individuals of endemic villages are usually affected therefore resulting in decreased agricultural productivity and economic hardship which often lead to rural-urban drift with its attending problems of overpopulation and increase in crime rate (Awayumi and Sowunmi, 2019).

Attitude: Towards the Guinea Worm Services| Health Workers and External Assistance Needed

The study shows that majority of respondents perceived the Guinea worm eradication program as being useful (96\%)). This may be explained by the fact that most respondents at least attended school hence had abetter vision of issues. Hypothesis testing shows that gender, age, ethnicity, and Education level did not significantly influence respondent's attitude towards Guinea worm eradication program.

The negative attitude towards the health workers was perceived by a large proportion of respondents (61\%) because some were genuinely unkind and rude. Respondents also reported to wait for long for the service at the health facility because of worker over load in health centre. This finding is similar to that of Yohalem, (1990) It has been high lighted by WHO, (1998), that many cultures are reluctant to use health services because they perceive health care providers to be rude.

Many respondents (43\%) perceived that the external assistance needed was technical support to educate people on prevention of Guinea worm. This overlaps with Nordberg, (1999) who reported that the most important measure in Guinea worm prevention is to educate the population. The finding also agree with David, (1990) who mention that community education is especially critical since the overall objective of the Guinea worm eradication program is to promote WHO's goal of eradicating Guinea worm disease by 1995).

Few respondent ever attended seminar on Guinea worm (19\%)), the finding can be explained by the inefficiency of the Southern Sudan Guinea worm eradication program in the county yet majority of respondent are willing to attend at anytime in future (81.8\%). Awoyemi and Sowunmi, (2009) opined that health education intervention as the only means of controlling guinea worm disease often failed due to lack of social cohesion or of uncoordinated group-action

The study also indicated that most respondent's (36\%) said that conducting meeting with community members and mass awareness campaigns will encourage community to participate in eradication. That could be explained by a large proportion of respondent's who obtained their information from health workers which could have explained to them the importance of mass community education and involvement. The findings agree with Erik, (1999) who revealed that prevention and control of Guinea Worm is an example of a condition that can be eradicated if there is stability and community education and involvement. Also similarly the Key Informants guide confirmed that community can be encourage by community sensitization. Also agree with the (SSGWEP, 2009) high lighted that the involvement and participation of all community and stakeholders to eradicate Guinea worm, is the key to success. Guinea worm eradication is about partnership, the most important of which is the partnership between the eradication program and the community.

Practice of Respondent towards Guinea worm Prevention and Treatment

The study findings indicate that more than a half of respondents (58\%) said that prohibiting patient from entering water sources is a means of Guinea worm prevention, this could be explained by the big number of respondent's who reported to obtains their information from 
health worker. Abran in 1995 exemplified that one of measures of controlling Guinea worm is that cases are advised not to enter drinking water sources while worm is emerged.

Majority respondents (59\%) said that they took patient to traditionalist/herbalist, this finding is similar to the one of Awayumi and Sowunmi, (2019) which stated that substantial numbers of respondents (68\%) combined traditional methods of treating the disease with orthodox methods while (33\%) took the person to the hospital and few (10\%) did nothing.

Additionally, because of the rural settings of the study areas, a large proportion of respondents (61\%) traditionally treat Guinea worm by putting the leg on cool water in the morning and winding the worm on wire, while few (39\%) reported bandaging the wound and wind the worm on stick, this could be explained by the fact that they learnt from the health volunteer, who have knowledge about this treatment method.

Lesthan a half of respondents (45\%) said that they filtered their water before drinking; the finding is comparable with Morinikeji and Adoklu, (2009) which shows that the water treatment mostly practiced by the respondents was filtration. The quarter of respondent's that do not treat their drinking water are still exposed or at risk of Guinea worm infection. During the key informants interview, it was affirmed that some respondent's drink water without treatment because they consider the addition of chemical to add bad smell to the water. Some were reported to drink water without treatment during grazing and from or to their fair where there is no access to safe water where by they practice sedimentation which can't remove the Cyclops. Omar and William, (1994) affirm in a study carried out in central equatorial state that almost 60 percent of Juba households are using untreated water from the river or stream (Khors) as their main sources.

The purpose of filtering cloth was clearly identified by most respondent's (47\%) who reported that removing Cyclops was the main purpose of filtering cloth, this could be explained by the fact that most respondent obtained their information from health workers, while a quarter of respondent's perceived that cleaning and purifying water as purpose of filtering cloth could still be consider knowing the purpose of filtering cloth and few (20\%) don't know the purpose of filtering cloth. This could be explained by the fact that more than a quarter of respondent's never attended school and the majority of respondent's who have never attended seminar.

This study was prompted by the need to investigate knowledge, attitude and practice towards Guinea worm based on premise that the spread of guinea worm disease is as a result of simple human behaviour related to water use and the fact that government financial resources have dwindled and provision of adequate safe water.

\section{Conclusion}

The study show that the 2009 eradication deadline to stop transmission in all remaining endemic communities by 2009 was not met due to present of new cases in most of communities.

Education level was found to be strongly associated with knowledge on the cause of infection of Guinea worm ( $\mathrm{p}>0.000)$.

More than a quarter of respondent's (36\%) family member had fallen victim of Guinea worm

A large proportion of respondent (56\%) perceived drinking infected water as a cause of Guinea worm infection.

Majority of respondent (76\%) said someone with G.W has very much difficulty in farming because an inching and painful blister develops at the place where the adult female worm emerge, thus making an ulcer

Most (43\%) of respondent's obtained drinking water from River/Stream and more than a quarter from ponds

The major sources of information to the respondent are the health workers when the respondent's go to the facilities for services or sharing experience with relatives. 
Texila International Journal of Public Health

Volume 4, Issue 4, Dec 2016

The majority (96\%) of respondents have positive attitude towards the Guinea worm eradication program, however their perception of the health workers is bad because they Health workers to be rout and unkindly.

Many respondents (58\%) preferring taking patients of Guinea worm to traditionalist/herbalist, who they think are cheaper, quicker or better.

There was statistically significant association between the education level and attitude, practise of respondent's in Juba County.

\section{Recommendations}

Both focused and integrated health education by the health workers need to be emphasized stressing to the communities the importance of Guinea worm eradication. This can be done both at Community level through resource persons such as parish (Buma) development committees as well as political, civic, and opinion leaders and the health unit and through specific and integrated outreaches such as immunization or mass awareness to cover three messages: That Guinea worm comes from contaminated water, Villagers should prohibit a person with blisters or ulcer from entering source of drinking water and that drinking water should be filtered or boiled before drinking.

The MOH should ensure that health workers change their behaviour towards the respondent's by being kind and helpful to them as away of encouraging them to participate in Guinea worm eradication program.

The $\mathrm{MOH}$ as well as the County administration should improve on the staffing at the health facilities so that there are enough staffs to handle the mothers immediately they come, in a bid to reduce on the waiting time.

The County Health Team Serious efforts should be made to ensure comprehensive hydro geological analysis for the suitability of sustainable boreholes which will in turn enhance uninterrupted water supply. However, where cost of sinking boreholes is unbearable field health workers should ensure that ponds are regularly treated with Abeat and water filter made available to residents of the areas that are prone to the disease.

The state authorities should strategically encourage activities that bid to uplift the education level of the respondent's. The authorities should as well gear up the governments activities in order to raise the social economic status of the people as this will also improve on the KAP of respondent's towards Guinea worm.

Support supervision and monitoring and evaluation of all health units offering health services as well as the village volunteers by the County Health Team need to be intensified.

\section{Proposed work plan and budget}

\begin{tabular}{|l|l|l|l|}
\hline No & ACTIVITY & TARGET & BUDGET(USA, Dollars) \\
\hline 1 & Communication and Transport & & 500 \\
\hline 2 & $\begin{array}{l}\text { Development of research } \\
\text { proposal }\end{array}$ & 1st September & 50 \\
\hline 3 & Literature review development & 1st October & 200 \\
\hline 4 & Development of questionnaire & 1st November & 50 \\
\hline 5 & Training of research assistant & 15th November & 50 \\
\hline 6 & Incentive for the Assistant & & 200 \\
\hline 6 & Data collection & 1st December & 200 \\
\hline 7 & Data Analysis & 15th December & 100 \\
\hline 8 & Discussion and writing of report & 15th December & 50 \\
\hline
\end{tabular}


Texila International Journal of Public Health

Volume 4, Issue 4, Dec 2016

\begin{tabular}{|l|l|l|l|}
9 & Final report & 20th December & 200 \\
\hline 10 & Total & & 1400 \\
\hline
\end{tabular}

\section{Acknowledgements}

I wish to acknowledge the following without whom the success of this research could have been impossible.

Almighty Allah, who has protected and guided me through out the period of this work, Special thanks go to Mr. Ng'ang'a Peter who supervised me in the course of this dissertation.

The Director of Southern Sudan Guinea worm eradication program for the support they offered me during this exercise.

The Director of Guinea worm eradication program central eradication state Juba Mr. Samson Sebit and other colleagues in the department for their spiritual and technical support, which were immense during this research.

The deputy director of EPI, central equatorial state Mr. Abdullah Abdurrahman.

Special thanks go to my Mother, my brother Habib, my sisters Zeinab and Haram who has put all their efforts to see that I succeed in my education till this level.

I cannot forget to thank my fellow colleques for guiding me through out my work not forgetting all the lecturers in the department of Masters of Public Health -KIU.

Last but not least my research assistants for their commitment and tireless efforts especially during the phase of data collection for this research.

May Allah reward you all abundantly.

\section{References}

[1]. Awayumi T.T and F.A. Sowunmi ( 2019), Socio-economic burden of Guinea worm in Oguni state : A discriminant analysis approach, African Journals of Agricultural Research, vol (4) pp 1138

[2]. Abran S.Benenson, (1995), control of communicable diseases manual, pp 157- 159

[3]. Centres for Disease Control Memorandum, (2007 February), Guinea Worm Wrap-up No 170. WHO Collaborating Center for Research, Training and Eradication of Dracunculiasis.

[4]. Communicable Diseases (CDS) and Water, Sanitation and Health unit (WSH), (2001), World Health Organization (WHO). 2001 (World Water Day).

[5]. Centres for Disease Control Memorandum, (2010 March), Guinea Worm Wrap-up No 170. WHO Collaborating Center for Research, Training and Eradication of Dracunculiasis.

[6]. Cairncross, Sandy; Muller, Ralph; Zagaria, Nevio (2002), Dracunculiasis (Guinea Worm Disease) and the Eradication Initiative” Clinical Microbiol Rev.; 15(2): 223-246.

[7]. Centres for Disease Control Memorandum, (2003 October), Guinea Worm Wrap-up No 136. WHO Collaborating Center for Research, Training and Eradication of Dracunculiasis.

[8]. WHO Collaborating Center for Research, (2001) Centres for Disease Control Memorandum (2001 November). Guinea Worm Wrap-up No 118, Training and Eradication of Dracunculiasis.

[9]. Carter Center, (2004), annual report, Carter Center 2004

[10]. David Yohalem, (1990), Programming Guide for Guinea Worm Eradication, Bureau for Science and Technology, U. S. Agency for Imitational Development under WASH Task No. 091.

[11]. Erik Nordberg, (1999), Communicable disease, AMREF, Kenya, PP 136-138

[12]. Southern Sudan Guinea worm eradication program, (2010), WHO Collaborating Center for Research, Training and Eradication of Dracunculiasis

[13]. John B. Rwakimari, Donald R. Hopkins and Ernesto Ruiz-Tiben, (2006), Uganda's Successful Guinea Worm Eradication Program, MOH Uganda, the American Society of Tropical Medicine and Hygiene pp 3

[14]. John M. Hunter, (1997), Geographical patterns of guinea worm infestation in Ghana, An historical contribution, Social Science \& Medicine, Volume 44, Issue 1, Pp 103-122. 
Texila International Journal of Public Health

Volume 4, Issue 4, Dec 2016

[15]. Karin E. Ekulund and Ann H. Davitsen and Taraf Hasvold, (2003), Teaching populations as means of improving general health, University of Tramso-Gana

[16]. Kelly JK and Pereira G (2006), "The problem of wate contamination with Dracunculus medinensis in southern Sudan” Journal of Rural and Tropical Public Health 5: 49-58, WHO Collaborating Center for Research, Training and Eradication of Dracunculiasis 2007.

[17]. Morenikeji Olajumoke and Adekolu Abimbola, (2009), Progress in Dracunculiasis Eradication: Ogun State, South-West Nigeria as Case Study, Journal of American Science, pp 189-193

[18]. Ministry of Health, Southern Sudan, Annual report( 2009), Ministry of Health, Southern Sudan Juba

[19]. Ministry of Health, Southern Sudan, (2008) Program Review Meeting, 2008, Ministry of Health, Southern Sudan Juba

[20]. Olunjde M.G., (2008), Farmers' Attitude to Nigerian Guinea Worm Eradication Health Education Programmes, Department of Agricultural Extension and Rural Development, University of Ibadan.

[21]. Omar S.Ertur and William J. House, (1994), Population and Human resources development in the Sudan, pp 154

[22]. Olajumoke A. Morenikeji, (2010) the Final Hurdle To Be Crossed In the Eradication of Dracunculiasis in Nigeria, Journal of American Science, 6(2).

[23]. Pedro.N.Acha and Boris Syfres, (1987), Zoonoses and communicable disease common to men and man, second addition, PAN American Organization, pp 792-797

[24]. Ralph Muller, (2005), Guinea worm disease -the final chapter, trends in Parasitology, volume 21, Issue 11, November 2005, pp 521- 524

[25]. Sandy Cairncross, Ralph Muller, and Nevio Zagaria,(2002), Dracunculiasis (Guinea Worm Disease) and the Eradication Initiative, American Society for Microbiology

[26]. Southern Sudan Guinea worm eradication program, (2009), Sudan people liberation Army Sensitization Workshop,16 October (2009), Juba

[27]. Susan Watts,(1998), Perceptions and priorities in disease eradication: Dracunculiasis eradication in Africa, Journals of Social Science \& Medicine, Volume 46, Issue 7,1 Pages 799-810

[28]. WHO, (2005), GUINEA WORM WRAP-UP, Collaborating Center for Research, Training and Eradication of Dracunculiasis,

[29]. WHO, (1998), world health day, safe mother hood journal, vol 98.1. 1, 215,21

[30]. WHO,(2008) Collaborating Center for Research, Training and Eradication of Dracunculiasis, Guinea worm wrap up( 179)Number of uncontained cases of dracunculiasis outside of Southern Sudan so far in 2008: 12 (Ghana), memorandum, February 25, 2008.

\section{Chi-square $\left(\mathrm{X}^{2}\right)$ analysis}

Chi-square $\left(\mathrm{X}^{2}\right)$ analysis of age, sex, Ethnicity and Education level and usefulness of Guinea worm eradication program is statistically not significant.

\begin{tabular}{|l|l|l|l|l|}
\hline Variable & Chi-square & D.F & P-value & Remarks \\
\hline Sex & 0.061 & 1 & 0.805 & NS \\
\hline Age & 38.833 & 2 & 0.301 & NS \\
\hline Ethnicity & 0.314 & 2 & 0.855 & NS \\
\hline Education & 2.919 & 3 & 0.404 & NS \\
\hline
\end{tabular}


Texila International Journal of Public Health

Volume 4, Issue 4, Dec 2016

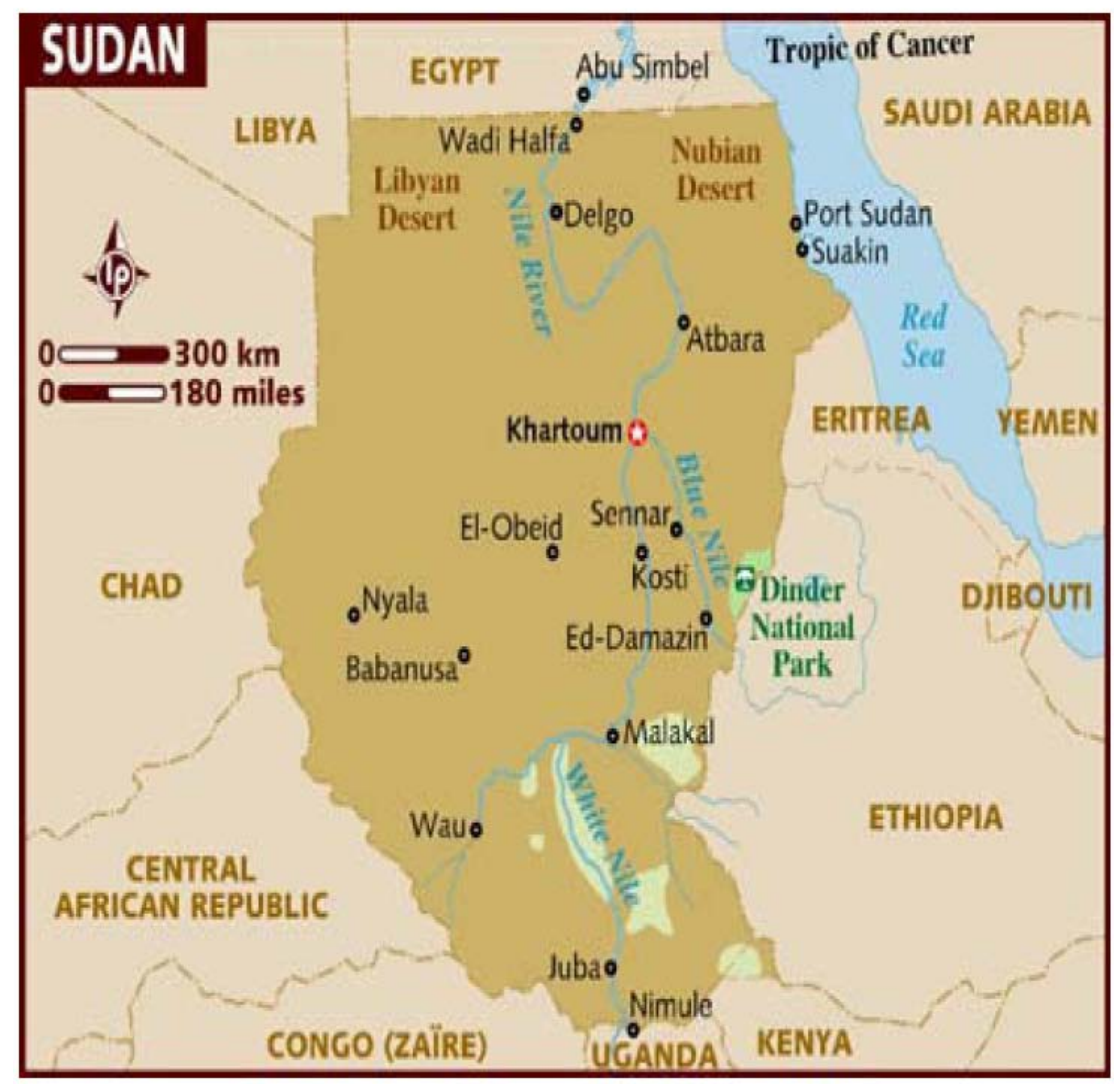

